\title{
Epoxidized natural rubber and hydrotalcite compounds: rheological and thermal characterization
}

\author{
Vanessa Macedo da Silva ${ }^{1,2}$, Regina Célia Reis Nunes ${ }^{1 *}$ and Ana Maria Furtado de Sousa ${ }^{3}$ \\ 'Instituto de Macromoléculas Professora Eloisa Mano - IMA, Universidade Federal do Rio de Janeiro - \\ UFRJ, Rio de Janeiro, RJ, Brazil \\ ${ }^{2}$ Centro Universitário Estadual da Zona Oeste - UEZO, Rio de Janeiro, RJ, Brazil \\ ${ }^{3}$ Departamento de Processos Químicos, Instituto de Química, Universidade do Estado do Rio de Janeiro \\ - UERJ, Rio de Janeiro, RJ, Brazil \\ *rcnunes@ima.ufrj.br
}

\begin{abstract}
Epoxidized natural rubber (ENR) and synthetic non-modified hydrotalcite (HT) compounds were prepared and evaluated. Natural rubber (NR) was epoxidized with $20.6 \%$ of epoxy groups from a chemical modification of the latex. A sulfur-based curing system formulation with accelerators was used. The amounts of HT in the ENR-HT compositions was varied between $0,2,3$ and 5 phr. All compositions were evaluated as to cure parameters, rheological properties, thermal resistance and crosslink density. The results showed that the mineral filler does not have a significant influence on the cure parameters. Different methods of crosslink density determination were used (swelling at equilibrium and elastic modulus). The results turn out to be equivalent and rise as the amount of filler is increased. The best results were found for the $5 \mathrm{phr}$ hydrotalcite compound (ENR-HT5).
\end{abstract}

Keywords: crosslink density, epoxidized natural rubber, layered double hydroxide, rheological behavior, thermal behavior.

\section{Introduction}

Layered double hydroxides (LDH), known as anionic clays, are minerals having positively charged layers interleaved with ions and water molecules, so as to maintain neutrality of charge. Anionic clays are not abundant in nature and hydrotalcite $\left(\mathrm{Mg}_{6} \mathrm{Al}_{2}(\mathrm{OH})_{16} \mathrm{CO}_{3} \cdot 4 \mathrm{H}_{2} \mathrm{O}\right)$ is an example of anionic clay found in nature. Properties like lamellar structure, ease of synthesis and readily controllable particle size are characteristics that have attracted researchers to study LDH and their applications on polymers, especially elastomers ${ }^{[1]}$.

The use of LDH in polymer matrices has been directed to different purposes. In nanocomposites, organically-modified LDH was studied to improve thermal resistance and inflammability properties ${ }^{[2]}$. The capacity to act like a crosslink agent for different kinds of elastomers has been studied aiming at replacing zinc oxide in rubber formulations ${ }^{[3,4]}$.

Chemical modification of natural rubber, especially epoxidation reaction, is a versatile route to obtain a polymer with better properties comparative to unmodified natural rubber like oil and organic solvent resistance, air permeability and performance for wet roads (for tire applications) $)^{[5]}$. The introduction of epoxy groups into NR chains increases the polarity of ENR and improves the compatibility of this polymer with polar fillers or blends with polar polymers ${ }^{[6]}$.

In this work hydrotalcite was studied in compositions of epoxidized natural rubber synthetized in our laboratory. The effect of the hydrotalcite content on cure characteristics, rheological properties and on thermal resistance was investigated. Also, for the sake of comparison, crosslink density was studied by two different methods.

\section{Materials and Methods}

\subsection{Materials}

High ammonia natural rubber latex (NRL) and $60 \%$ of dry rubber content was supplied by Teadit. Nonionic surfactant Ultranex 95 (ethoxilatednonylphenol), supplied by Oxiteno, was used to stabilize NRL during the epoxidation reaction. Magnesium aluminium layered double hydroxide (hydrotalcite) was obtained from Sigma Aldrich and used in its unmodified form. Double ventilated sulfur, Irganox 1010 (Pentaerythritoltetrakis(3-(3,5-di-tert-butyl-4-hydro xyphenyl)propionate)), stearic acid, zinc oxide and TBBS (N-tert-butyl-2-benxothiazolesulfenamide) were used for the curing process. The other chemical products used in this work were formic acid, hydrogen peroxide $30 \%$, ethanol $95 \%$, anhydrous sodium carbonate, toluene and chloroform, all obtained from Sigma.

\subsection{Methods}

\subsubsection{Characterization of hydrotalcite}

Infrared spectra were collected in a Varian 3100 FT-IR equipment using a total reflection attenuated accessory, between 600 and $4000 \mathrm{~cm}^{-1}$, mode transmittance, $4 \mathrm{~cm}^{-1}$ of resolution and 100 scans.

Thermal stability was studied using a thermogravimetric analyser (TGA) Q500 from TA Instruments, between $30^{\circ} \mathrm{C}$ and $700^{\circ} \mathrm{C}$ at $10^{\circ} \mathrm{C} /$ minute under inert atmosphere (nitrogen). 


\subsubsection{Chemical modification of $\mathrm{NRL}$ - Epoxidation reaction}

Epoxidized natural rubber (ENR) was obtained containing $20 \%$ of epoxy groups as described in ${ }^{[7]}$ with some modifications. NRL, previously stabilized with surfactant, was epoxidized using organic peracid obtained in situ by the reaction between formic acid and hydrogen peroxide. The reaction was processed during 8 hours at $70^{\circ} \mathrm{C}$. In the end, the $\mathrm{pH}$ of the epoxidized latex was neutralized by addition of anhydrous sodium carbonate solution, coagulated, dried and characterized.

\subsubsection{Characterization of epoxidized natural rubber (ENR)}

The chemical structure of ENR was investigated in a Varian 3100 FT-IR equipment, between 500 and $4000 \mathrm{~cm}^{-1}$, resolution of $4 \mathrm{~cm}^{-1}$ and 32 scans. The polymer film for analysis was obtained after chloroform evaporation of solubilized ENR.

Epoxy groups content was determined by hydrogen nuclear magnetic resonance $\left({ }^{1} \mathrm{HNMR}\right)$ in a Varian Mercury VX300 instrument with $300,5 \mathrm{~Hz}$ of frequency. For the tests, the ENR polymer was solubilized in deuterated chloroform.

\subsubsection{ENR/Hydrotalcite compounds preparation}

ENR/Hydrotalcite compounds were prepared in a LRMR-S two-roll mixing mill by TECH Engineering Company LTD at $30^{\circ} \mathrm{C}$ according to ASTM D3184. The formulations studied were (in phr): ENR 100.0; stearic acid 2.0; zinc oxide 5.0; sulfur 2.5; TBBS 1.5; Irganox 1010 1.0. The hydrotalcite content varied between $0,2,3$ and $5 \mathrm{phr}$. Compounds were identified as ENR-HT0, ENR-HT2, ENR-HT3, ENR-HT5 corresponding respectively $0,2,3$ and 5 phr of hidrotalcite.

\subsubsection{Rheometric properties}

The rheometric parameters of the compounds were studied using an Alpha Technologies RPA2000 rubber process analyzer. Tests were processed according to ASTM D5289 at $150^{\circ} \mathrm{C}$, oscillating $\operatorname{arc} 1^{\circ}$ and $1.7 \mathrm{~Hz}$ of frequency during 60 minutes. As for torque, the measurement tolerance is $0.5 \%$ of the working range and for the temperature, accuracy is $\pm 0.3^{\circ} \mathrm{C}$ of the test temperature.

\subsubsection{Rheological properties - Sweep temperature}

The compounds cure was studied by sweep temperature using a RPA 2000 Analyser between 50 and $200^{\circ} \mathrm{C}, 5^{\circ} \mathrm{C}$ /minute of heating rate, $0.5^{\circ}$ of strain and $1 \mathrm{~Hz}$ of frequency.

\subsubsection{Thermal properties}

The thermal stability of compounds was studied using a thermogravimetric analyzer (TGA) Q500 from TA Instruments between $30^{\circ} \mathrm{C}$ and $700^{\circ} \mathrm{C}$ at $10^{\circ} \mathrm{C} /$ minute under inert atmosphere (nitrogen).

\subsubsection{Crosslink density}

Crosslink density was determined using two methods, comparatively. One of then was the method based on swelling resulting from contact with an organic solvent as reported in Flory studies ${ }^{[8]}$ and the other one was based on the rheological property of elastic modulus ( $\left.\mathrm{G}^{\prime}\right)$, obtained by the RPA 2000 Analyser ${ }^{[9]}$.

\subsubsection{Swelling method}

Specimens of $20 \mathrm{~mm} \times 20 \mathrm{~mm} \times 2 \mathrm{~mm}$ were immersed in toluene kept in closed containers in the dark during 7 days. The swollen rubber volume $\left(\mathrm{V}_{\mathrm{r}}\right)$ was measured based on Equation 1 developed by Flory-Rehner ${ }^{[8]}$.

$$
V_{r}=\left(\frac{W_{1}}{\rho_{2}}-\frac{W_{h}}{\rho_{h}}\right) /\left\{\left(\frac{W_{1}}{\rho_{2}}-\frac{W_{h}}{\rho_{h}}\right)+\left[\left(\frac{W_{2}-W_{3}}{\rho_{1}}\right)\right]\right\}
$$

Where $\mathrm{V}_{\mathrm{r}}$ is the swollen rubber volume; $\mathrm{W}_{1}$ is the sample weight before swelling; $\mathrm{W}_{2}$ is the swollen sample weight; $\mathrm{W}_{3}$ is the dried sample weight; $\mathrm{W}_{\mathrm{h}}$ is the hydrotalcite weight in the sample; $\rho_{1}$ is the solvent density; $\rho_{2}$ is the sample density; $\rho_{\mathrm{h}}$ is the hydrotalcite density.

It is possible to measure the crosslink density through the rubber volume in a swelling network, as described in Equation 2.

$$
=-\left[\ln \left(1-V_{r}\right)+V_{r}+. V_{r}^{2}\right] / V_{0}\left(V_{r}^{1 / 3}-\frac{V_{r}}{2}\right)
$$

Where $v$ is the number of chains inside the reticulum in $\mathrm{mol} / \mathrm{cm}^{3} ; \chi$ is the interaction parameter between toluene and epoxidized natural rubber $(\chi=0.39) ; \mathrm{V}_{0}$ is the molar volume of the solvent $\left(\mathrm{V}_{0}=106.2\right)$.

\subsubsection{Rheological properties method}

To measure crosslink density by rheological properties, the elastic modulus $\left(G^{\prime}\right)$ was determined for uncured and cured compounds at $100^{\circ} \mathrm{C}, 0.25^{\circ}$ of strain, $5 \mathrm{~Hz}$ and $0.5 \mathrm{~Hz}$, respectively, using a RPA 2000 Analyser ${ }^{[9]}$. Through this method it is possible to measure the physical crosslink density $\left(\mathrm{X}_{\text {initial }}\right)$ relative to entanglements and the total crosslink density $\left(\mathrm{X}_{\text {total }}\right)$, relative to entanglements plus chemical crosslinks. The values of $\mathrm{X}_{\text {initial }}$ and $\mathrm{X}_{\text {total }}$ can be obtained using Equations 3 and 4, respectively ${ }^{[9]}$.

$$
\begin{gathered}
X_{\text {total }}=\frac{G_{\text {cured }}^{\prime}(0.5 \mathrm{~Hz})}{2 R T} \\
X_{\text {initial }}=\frac{G_{\text {uncured }}^{\prime}(5 \mathrm{~Hz})}{2 R T}
\end{gathered}
$$

Where: $\mathrm{G}_{\text {cured }}$ is the elastic modulus measured at $0.5 \mathrm{~Hz}$ of frequency for cured compounds; $\mathrm{G}_{\text {uncured }}$ is the elastic modulus measured at $5 \mathrm{~Hz}$ of frequency for uncured compounds; $\mathrm{R}$ is the gases constant (8.31 L.KPa/K.mol); and $\mathrm{T}$ is the temperature in Kelvin degrees.

The elastic modulus ( $\left.G^{\prime}\right)$ values were corrected using the Guth-Gold Equation to determine the equivalent rubber modulus without any filler ${ }^{[9]}$. It was calculated through Equation 5.

$$
G_{\text {filled }}^{\prime}=G_{\text {unfilled }}^{\prime}\left(1+2.5 \varnothing+14.1 \varnothing^{2}\right)
$$

Where: $\varnothing$ is the effective volume fraction of filler. 


\section{Results and Discussions}

\subsection{Characterization of hydrotalcite}

The chemical structure of hydrotalcite was investigated using FT-IR. The infrared spectra (Figure 1) showed a large absorption band at $3416 \mathrm{~cm}^{-1}$ referred to hydroxyl groups and hydration water of the hydrotalcite structure. At $1365 \mathrm{~cm}^{-1}$ the asymmetric stretch of carbonate present between the hydrotalcite lamellae could be seen. The absorption bands located at $775 \mathrm{~cm}^{-1}$ and $637 \mathrm{~cm}^{-1} \mathrm{can}$ be attributed to magnesium oxide and aluminum oxide ${ }^{[10,11]}$.

The thermal stability of hydrotalcite was studied by TGA. Figure 2 showed three degradations steps. The first one, between $50^{\circ} \mathrm{C}$ and $230^{\circ} \mathrm{C}$, was referred to the loss of absorbed water and interlayer water. In step 2, between $230^{\circ} \mathrm{C}$ and $370^{\circ} \mathrm{C}$, the degradation of interlayered carbonate and the loss of hydroxyl groups associated to aluminum and magnesium was observed. Between $370^{\circ} \mathrm{C}$ and $550^{\circ} \mathrm{C}$, in step 3 , the total degradation of hydroxyl groups of metals happened simultaneously forming metallic oxides $\left(\mathrm{Al}_{2} \mathrm{O}_{3}\right.$ and $\left.\mathrm{MgO}\right)$ and steam ${ }^{[11]}$.

\subsection{Characterization of epoxidized natural rubber}

The epoxidation of natural rubber latex was confirmed by infrared spectroscopy (Figure 3). Absorption bands at $1249 \mathrm{~cm}^{-1}$ and $870 \mathrm{~cm}^{-1}$ refer to symmetric and asymmetric deformations by epoxy rings, respectively ${ }^{[12]}$.

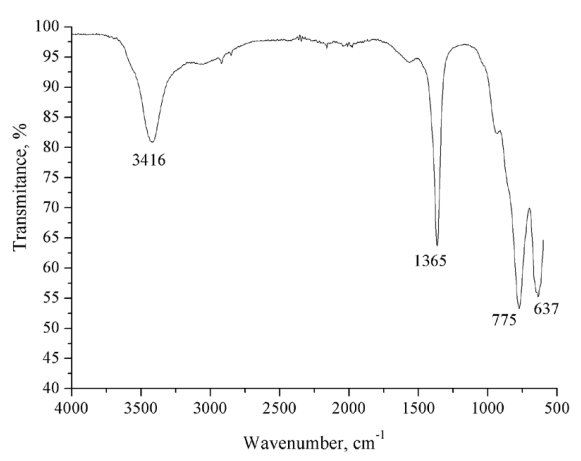

Figure 1. Infrared spectra of hydrotalcite.

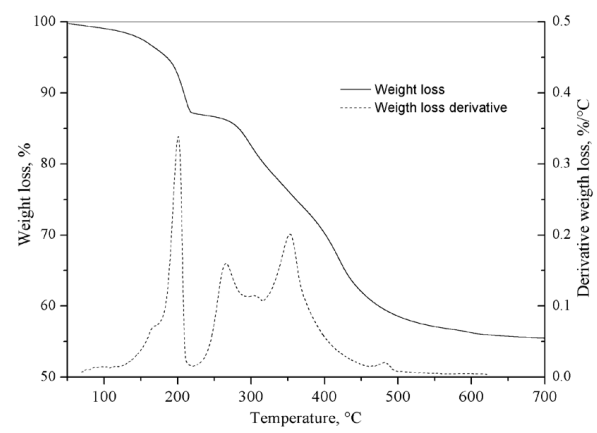

Figure 2. Weigth loss derivative curves of Hydrotalcite.
The efficiency of the chemical modification of natural rubber latex was investigated by ${ }^{1} \mathrm{HNMR}$. The spectrum of the polymer (Figure 4) showed chemical shifts at $2.7 \mathrm{ppm}$ and $5.1 \mathrm{ppm}$ referred to the methine hydrogen of epoxy rings and olefin hydrogen of cis-1,4-polyisoprene, respectively. Chemical shifts referred to methyl and methylene groups adjacent to the epoxy ring were located at $1.6 \mathrm{ppm}$ and $2.1 \mathrm{ppm}$, respectively ${ }^{[13,14]}$. The area ratio of signals at $2.7 \mathrm{ppm}$ and $5.1 \mathrm{ppm}$, as described in Equation 6, yielded the epoxidation content of $20.6 \%{ }^{[14]}$.

$$
\text { Epoxidation } \%=\left[\text { Area }_{2.7} \mathrm{ppm} /\left(\text { Area }_{2.7} \mathrm{ppm}+\text { Area }_{5.1 \mathrm{ppm}}\right)\right] .100
$$

\subsection{Rheometric properties}

The rheometric parameters of ENR-HT compounds are shown in Table 1.

Generally, the rheometric parameters did not show significant difference. This means that filler addition did not influence negatively on kinetics cure. Also, it indicates that the compounds have the same crosslink density.

\subsection{Rheological properties - Sweep temperature}

Elastic torque curves of the sweep temperature study (Figure 5) showed that the presence of hydrotalcite did not influence the rheometric parameters, considering the amounts used in this work, corroborating the rheometry tests. The torque values decrease with increasing temperature.

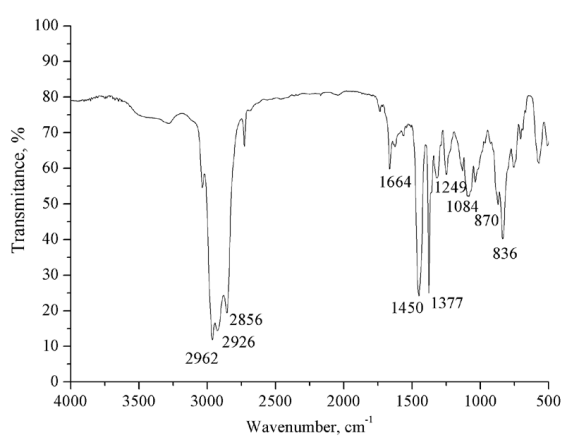

Figure 3. Infrared spectra of ENR.

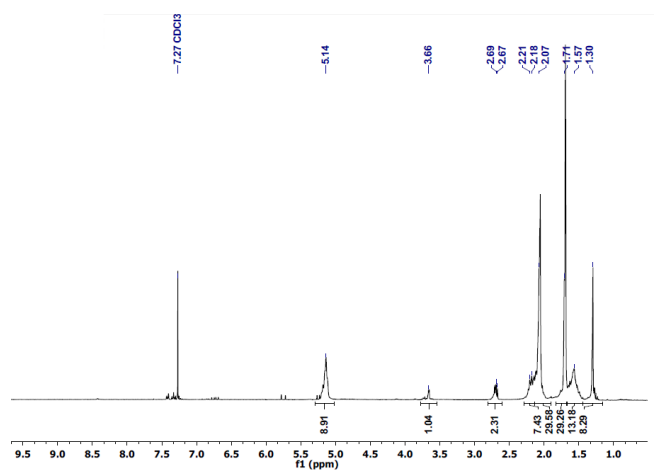

Figure 4. $\mathrm{H}^{1}$-NMR spectra of ENR. 
Table 1. Rheometric characteristics of ENR-HT compounds.

\begin{tabular}{cccccc}
\hline $\begin{array}{c}\text { Rheometric } \\
\text { characteristics }\end{array}$ & $\mathbf{t}_{\mathbf{s 1}}(\mathbf{m i n})$ & $\mathbf{t}_{\mathbf{9 0}}(\mathbf{m i n})$ & $\mathbf{M}_{\mathbf{L}}(\mathbf{d N m})$ & $\mathbf{M}_{\mathbf{H}}(\mathbf{d N m})$ & $\mathbf{M}_{\mathbf{H}}-\mathbf{M}_{\mathbf{L}}(\mathbf{d N m})$ \\
\hline ENR-HT0 & 2.3 & 5.3 & 0.2 & 21.8 & 21.6 \\
ENR-HT2 & 2.3 & 4.8 & 0.2 & 21.7 & 21.5 \\
ENR-HT3 & 2.1 & 4.9 & 0.2 & 21.7 & 21.5 \\
ENR-HT5 & 2.0 & 5.4 & 0.1 & 21.7 & 21.6 \\
\hline
\end{tabular}

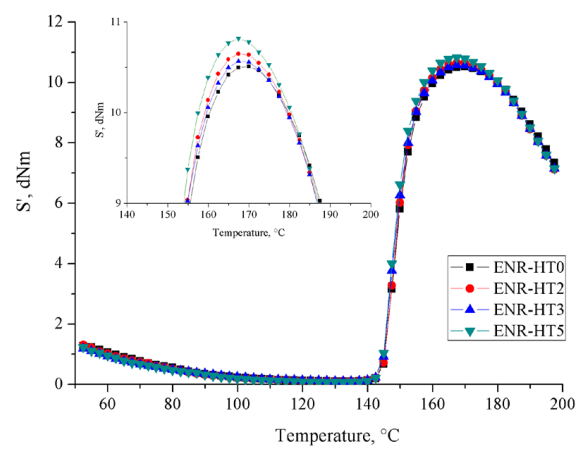

Figure 5. Curves of elastic torque versus temperature of ENR-HT compounds.

The initial torque is $1.3 \mathrm{dNm}$ at $50^{\circ} \mathrm{C}$ and it decreases to 0.1 at $140^{\circ} \mathrm{C}$. This is due to the fact that the polymer chain acquires molecular mobility and, consequently, lower flow resistance. As from $140^{\circ} \mathrm{C}$ a significant increase in torque values with increasing temperature was observed. It resulted from crosslink formation, making compounds more rigid. The maximum torque was obtained at $167^{\circ} \mathrm{C}$ and from that temperature on, torque decreased until $7 \mathrm{dNm}$ at $200^{\circ} \mathrm{C}$, when the test was stopped. A slightly increase in maximum torque was observed as a function of the hydrotalcite amount in the compound.

The sweep test showed that different compositions presented the same cure kinetics. By relating sweep temperature curves with Table 1 it was found that the differences observed in cure time were not significant and that the compositions keep the same behavior until $5 \%$ of hydrotalcite content.

\subsection{Thermal properties}

Table 2 shows compounds data for onset $\left(\mathrm{T}_{\text {onsee }}\right)$ and maximum temperature degradation $\left(\mathrm{T}_{\max }\right)$. It was observed that compounds containing hydrotalcite had lower thermal resistance. Compounds had lower initial temperature degradation $\left(\mathrm{T}_{\text {onser }}\right)$ as compared with a compound without filler (ENR-HT0). This fact could be related with the degradation of interlayer carbonates between 230 and $370^{\circ} \mathrm{C}$.

Derivative weight loss curves (Figure 6) showed shoulders at $420^{\circ} \mathrm{C}$ for hydrotalcite-containing compounds. This coincides with hydrotalcite dehydroxilation, when the hydroxyl bound to aluminum and magnesium is degraded.
Table 2. Thermal degradation temperatures.

\begin{tabular}{lcc}
\hline $\begin{array}{c}\text { Thermal degradation } \\
\text { temperatures }\end{array}$ & $\mathbf{T}_{\text {onset }}\left({ }^{\circ} \mathbf{C}\right)$ & $\left.\mathbf{T}_{\text {max }}{ }^{\circ}{ }^{\circ} \mathbf{C}\right)$ \\
\hline ENR-HT0 & 355 & 379 \\
ENR-HT2 & 350 & 374 \\
ENR-HT3 & 350 & 376 \\
ENR-HT5 & 348 & 375 \\
\hline
\end{tabular}

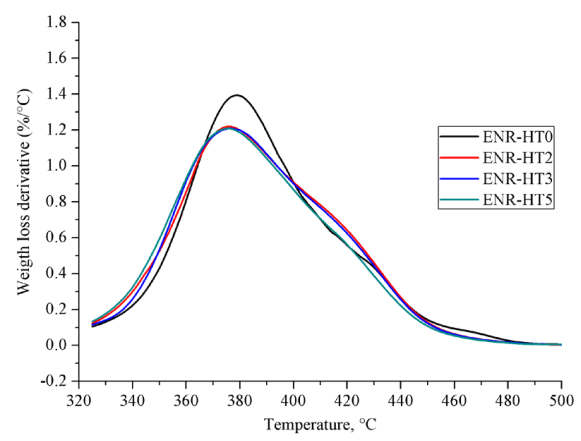

Figure 6. Weigth loss derivative curves of ENR-HT compounds.

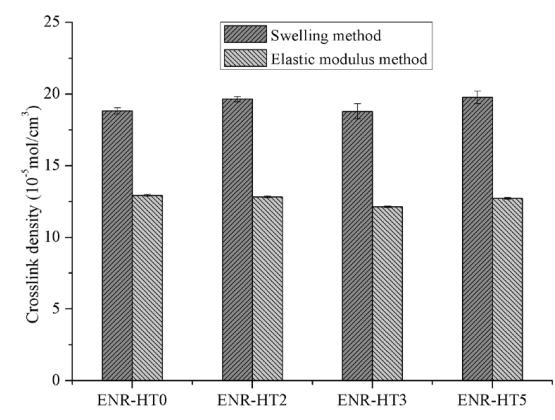

Figure 7. Crosslink density obtained by sweeling and elastic modulus method.

\subsection{Crosslink density}

Comparative results of two different methods to obtain crosslink density are described in Figure 7. It is shown that the hydrotalcite amount did not influence crosslink density, corroborating results described in Table 1. Although the results obtained by swelling and elastic modulus show different values it should be considered that such results show the same variation profile between compounds and they are similar. The analysis of crosslink density by elastic modulus properties is a fast and efficient alternative to 
measure that property. Also, it is ecofriendly because it does not make use of organic solvents harmful to human health and the environment.

\section{Conclusions}

Epoxidized natural rubber was synthetized with $20.6 \%$ of epoxy groups. The presence of hydrotalcite in rubber compounds did not affect the cure kinetics comparatively with compounds without filler. Sweep temperature studies showed that all compounds cured at the same temperature and they showed a slightly increase in torque with hydrotalcite content. Thermal resistance of filler-containing compounds was lower than that of ENR-HT0 due to interlayer carbonates and hydroxyl metals of the hydrotalcite structure which undergo degradation. Crosslink density analyses have comparable results by swelling or modulus elastic method.

\section{Acknowledgements}

The authors are indebted to $\mathrm{CNPq}$, CAPES and FAPERJ for financial support and to Teadit Indústria e Comércio Ltda by supply of natural rubber latex, additives and further materials employed during the course of this research.

\section{References}

1. Basu, D., Das, A., Stockelhuber, K. W., Wagenknecht, U., \& Heinrich, G. (2014). Advances in layered double hydroxide (LDH) - based elastomer composites. Progress in Polymer Science, 39(3), 594-626. http://dx.doi.org/10.1016/j. progpolymsci.2013.07.011.

2. Pradhan, S., Costa, F. R., Wagenknect, U., Jehnichen, D., Bhowmick, A. K., \& Heinrich, G. (2008). Elastomer/LDH nanocomposites: synthesis and studies on nanoparticle dispersion, mechanical properties and interfacial adhesion. European Polymer Journal, 44(10), 3122-3132. http://dx.doi. org/10.1016/j.eurpolymj.2008.07.025.

3. Das, A., Wang, D.-Y., Leuteritz, A., Subramanian, K., Grenwell, H. C., \& Wagenknecth, U. (2011). Preparation of zinc oxide free, transparent rubber nanocomposites using a layered double hydroxide filler. Journal of Materials Chemistry, 21(20), 71947200. http://dx.doi.org/10.1039/c0jm03784b.

4. Laskowska, A., Zaborski, M., Gain, O., Marzec, A., \& Maniukeiwicz, W. (2014). Ionic elastomers based on carboxylated nitrile rubber (XNBR) and magnesium aluminum layered double hydroxide filler. Express Polymer Letters, 8(6), 374386. http://dx.doi.org/10.3144/expresspolymlett.2014.42.

5. Yu, H., Zeng, Z., Lu, G., \& Wang, Q. (2008). Processing characteristics and thermal stabilities of gel and sol of epoxidized natural rubber. European Polymer Journal, 44(2), 453-464. http://dx.doi.org/10.1016/j.eurpolymj.2007.11.016.

6. Gan, S.-N., \& Hamid, Z. A. (1997). Partial conversion groups to diols in epoxidized natural rubber. Polymer, 38(8), 19531956. http://dx.doi.org/10.1016/S0032-3861(96)00710-0.

7. Sanguansap, K., Suteewong, T., Saendee, P., Buranabunya, U., \& Tangboriboonrat, P. (2005). Composite natural rubber based latex particles: a novel approach. Polymer, 46(4), 1373-1378. http://dx.doi.org/10.1016/j.polymer.2004.11.074.

8. Flory, P. J. (1953). Principles of polymer chemistry. New York: Cornell University Press.

9. Lee, S., Pawlowsky, H., \& Coran, A. Y. (1994). Method for estimating the chemical crosslink densities of cured natural rubber and styrene-butadiene rubber. Rubber Chemistry and Technology, 67(5), 854-864. http://dx.doi.org/10.5254/1.3538716.

10. Othman, M. R., Rasid, N. M., \& Fernando, W. J. N. (2006). $\mathrm{Mg}$-Al hydrotalcite coating on zeolites for improved carbon dioxide adsorption. Chemical Engineering Science, 61(5), 1555-1560. http://dx.doi.org/10.1016/j.ces.2005.09.011.

11. Costa, F. R., Leuteritz, A., Wagenknetch, U., Jehnichen, D., Haubler, L., \& Heinrich, G. (2008). Intercalation of Mg-Al layered double hydroxide by anionic surfactants: preparation and characterization. Applied Clay Science, 38(3-4), 153-164. http://dx.doi.org/10.1016/j.clay.2007.03.006.

12. Chuayjuljit, S., Yaowasang, C., Ranomg-NA, N., \& Potiyaraj, P. (2006). Oil resistance and physical properties of in situ epoxidized natural rubber from high ammonia concentrated latex. Journal of Applied Polymer Science, 100(5), 3948-3955. http://dx.doi.org/10.1002/app.22998.

13. Saito, T., Klinklai, W., \& Kawahara, S. (2007). Characterization of epoxidized natural rubber by 2D NMR spectroscopy. Polymer, 48(3), 750-757. http://dx.doi.org/10.1016/j.polymer.2006.12.001.

14. Klinklai, W., Kawahara, S., Mizumo, T., Yoshizawa, M., Sakdapipanich, J. T., Isono, Y., \& Ohno, H. (2003). Depolymerization and ionic conductivity of enzymatically deproteinized natural rubber having epoxy group. European Polymer Journal, 39(8), 1707-1712. http://dx.doi.org/10.1016/ S0014-3057(03)00060-0.

Received: May 28, 2016

Revised: Jan. 13, 2017

Accepted: Feb. 21, 2017 